\title{
A legitimação da educação física escolar: a cultura corporal de movimento como linguagem e condição de possiblidade de conhecimento
} \author{
as a language and condition for the possibility of knowledge \\ Luis Eugênio Martiny ${ }^{1,4}$, Larissa Zanetti Theil ${ }^{2,4}$, Eloy Maciel Neto ${ }^{3,4}$ \\ ${ }^{1}$ Instituto Federal do Rio Grande do Norte (IFRN), Canguaretama, Brasil \\ 2 Instituto Federal Farroupilha (IFFAR), Santo Ângelo, Brasil \\ ${ }^{3}$ Secretaria de Educação de Pernambuco (SEE-PE), Recife, Brasil \\ ${ }^{4}$ Universidade de Coimbra (UC), Coimbra, Portugal
}

The legitimization of physical education at school: the body culture of movement

\section{HISTORICO DO ARTIGO \\ Recebido: 18 março 2021 \\ Revisado: 25 maio 2021 \\ Aprovado: 31 maio 2021}

\section{PALAVRAS-CHAVE:}

Cultura Corporal de Movimento; Educação; Educação Física; Legitimação.

\section{KEYWORDS:}

Body Culture of Movement; Education; Physical Education;

Legitimation.

\section{RESUMO}

INTRODUÇÃO: A Educação Física escolar construiu-se por meio de diferentes influências pedagógicas históricas que produziram interferências marcantes na escola, no fazer pedagógico dos profissionais imersos nesse contexto, e consequentemente, contribuíram para um estado de crise identitária da Educação Física.

OBJETIVO: Diante este cenário o objetivo principal deste estudo é a reflexão acerca da legitimidade da Educação Física como componente do currículo escolar.

MÉTODOS: Trata-se de um ensaio teórico que propõe a problematização da Educação Física escolar, com destaque para as intervenções pedagógicas dos conteúdos da cultura corporal de movimento. Primeiramente fez-se uma reflexão e discussão sobre o objeto de estudo da Educação Física, posteriormente sobre a sua relevância, seu lugar de pertencimento no sistema de ensino como componente curricular, e por último, sobre as suas condições de possibilidade de conhecimento a partir do saber científico e do saber do senso comum. RESULTADOS: A possibilidade de conhecimento da Educação Física e por conseguinte, sua legitimação, dar-se-á pela harmonização entre aquilo que a diferencia e aquilo que a integra, ou seja, do arranjo entre diferentes manifestações da cultura corporal do movimento e a linguagem.

CONCLUSÃO: É importante destacar que não se pretendeu produzir respostas prescritivas, porém é necessário produzir e discutir acerca da responsabilidade curricular da Educação Física como disciplina, trazendo à tona maiores esclarecimentos do universo representativo dessa área do saber. Para além, tem-se consciência que este estudo não colocará um ponto final em toda esta temática. Antes pelo contrário, é um ponto de partida para que se possa realizar novas investigações e intervenções pedagógicas que consigam explorar os conteúdos da cultura corporal de movimento nas aulas de Educação Física.

\section{ABSTRACT}

BACKGROUND: School Physical Education was built through different historical pedagogical influences that produced marked interferences in the school, in the pedagogical practice of professionals immersed in this context, and, consequently, contributed to a state of identity crisis in Physical Education.

OBJECTIVE: In view of this scenario, the main objective of this study is to reflect on the legitimacy of Physical Education as a component of the school curriculum.

METHODS: This is a theoretical essay that proposes the problematization of school Physical Education, with emphasis on pedagogical interventions on the contents of body culture of movement. Firstly, there was a reflection and discussion about the object of study of Physical Education, later about its relevance, its place of belonging in the education system as a curricular component, and finally, about its conditions of possibility of knowledge from the scientific knowledge and common sense knowledge.

RESULTS: The possibility of knowledge of Physical Education and, therefore, its legitimation, will occur through the harmonization between what differentiates it and what integrates it, that is, the arrangement between different manifestations of the movement's body culture and language.

CONCLUSION: It is important to highlight that it was not intended to produce prescriptive responses, but it is necessary to produce and discuss the curricular responsibility of Physical Education as a discipline, bringing to the fore further clarifications from the representative universe of this area of knowledge. In addition, we are aware that this study will not put an end to this whole theme. On the contrary, it is a starting point for new investigations and pedagogical interventions that can explore the contents of body culture of movement in Physical Education classes. 


\section{INTRODUÇÃo}

[...] se nos propomos a perguntar pelo nosso conhecer, fica claro que estamos imersos num viver que nos ocorre na linguagem, na experiência de sermos observadores na linguagem. E insisto neste último ponto, porque se não estamos na linguagem não há reflexão, não há discurso, não dizemos nada, simplesmente somos sem sê-lo, até refletirmos sobre o ser (MATURANA, 2002, p. 38).

Esse ensaio parte da compreensão de que a Educação Física escolar (objeto central de reflexão) se configura a partir da linguagem do corpo, da sua gestualidade e da dimensão sensível que se expressa como possibilidade de arranjo para o conhecimento. Sendo assim, a Educação Física enquanto disciplina constitutiva do projeto pedagógico da escola viria para integrar uma proposta de trabalho que incorpore as dimensões afetivas, cognitivas e socioculturais dos(as) alunos(as). Delimitar-se-ia, portanto, a partir das práticas corporais que busquem democratizar, humanizar e diversificar a prática pedagógica da área, considerando os seus contextos históricos e culturais (GALLARDO, 2005).

Não obstante, em recortes históricos da Educação Física escolar, Grespan (2002), revela discursos contraditórios e antagônicos na prática dessa área do conhecimento. As várias tendências $^{1}$ registradas na história da Educação Física (EF), deixaram influências marcantes na escola, e consequentemente, no fazer pedagógico dos profissionais imersos nesse contexto. Muitos sentimentos de angústias e alívios, assim como, posturas de concordâncias e indignações, se manifestaram no transcorrer desse processo (SOUZA JUNIOR, 2005). Muitos desses conflitos ainda não se esgotaram e, certamente, não se esgotarão por aqui.

A Lei de Diretrizes e Bases - LDB (Lei n 9.394/1996) e a Lei complementar $n^{\circ}$ 10.328/2001 da educação brasileira, viabilizaram a integração da Educação Física à proposta pedagógica da escola, considerando-a como disciplina obrigatória na Educação Básica ${ }^{2}$, e que, portanto, aproximando-a de sua função social na instituição escolar. Todavia, ao assegurar sua legalidade, no intuito de absolutizar (dar por encerrada) as discussões sobre a sua presença na escola, Bracht et al. (2003) chamam a atenção para uma questão nevrálgica na $\mathrm{EF}$, a qual diz respeito à conquista de sua legitimidade, ou seja, a busca da produção de um convencimento de sua importância, uma justificativa de sua presença na escola para a sociedade.

Nesse sentido, na busca para se formular um consenso sobre a importância da EF na escola, a idéia que surge como necessária passa por um processo de problematizar essa EF escolar, com o objetivo de conseguir, por meio dessas discussões, um maior esclarecimento acerca do universo representativo dessa área do saber. Sua relação e responsabilidade com a sociedade, escola, educação e como disciplina pedagógica. O não a problematizar surge como a primeira alternativa para parar de pensar sobre ela.

Para Santos (1990 apud SOUZA JUNIOR, 2001, p. 82)

o desenvolvimento de uma disciplina deve ser compreendido como resultante das contradições dentro do próprio campo de estudos, o qual reflete e mediatiza diferentes tendências do campo educacional, relacionadas aos conflitos, contradições e mudanças que ocorrem na sociedade.

\footnotetext{
Higienista (até 1936), militarista (1930-1945), pedagogicista (1945-1964), competitivista (pós-1964) e popular (década de 70) (GUIRALDELLI JÚNIOR, 1989).
}

${ }^{2}$ Facultado ao ensino noturno
Deste modo, a partir de análises críticas sobre a presença da EF na escola e de sua legitimação como componente do currículo escolar, dois enfrentamentos necessitam de maior atenção. O primeiro deles diz respeito a aventurar-se em sinalizar qual é a especificidade da EF, ou seja, por menor que possa representar situar-se e posicionar-se sobre qual a área de conhecimento da $\mathrm{EF}^{3}$ (o seu núcleo identitário). Já, o segundo embate que se pretende desenvolver neste texto passa pelo processo de responder o porquê ensinar EF na escola? Por que ela faz parte do currículo escolar? Em outras palavras, quais seriam, portanto, as suas condições de possibilidade de conhecimento.

Diante desses questionamentos, ressalta-se a salutar importância em refletir o papel da EF na escola, por se acreditar que os saberes oriundos dessa área de conhecimento podem constituir componentes essenciais para a formação dos sujeitos envolvidos no processo educativo. Não obstante, pretende-se conjecturar sobre a EF escolar, buscando compreendê-la como componente curricular acerca de sua relevância no processo educacional. No entanto, as respostas para os questionamentos discorridos, certamente, não se esgotarão por aqui, uma vez que a produção do conhecimento se revela num processo dinâmico, suscitando, continuamente, e por meio de novas reflexões.

\section{0 que é educação física?}

"Perguntar o que é Educação Física só faz sentido, quando a preocupação é compreender essa prática para transformá-la" (COLETIVO DE AUTORES, 1992, p. 50).

Para buscar uma melhor compreensão do que é a Educação Física, neste momento é importante destacar que não se objetiva resolver os problemas de especificidade da área ${ }^{4}$. O que se está propondo é a apresentação de algumas verdades frágeis, ou como diria Soares (1996, p.6), "um apanhado de dúvidas e de algumas certezas provisórias".

Neste sentido, ao tentar compreendê-la, delimita-se suas concepções às práticas corporais institucionalizadas e sistematizadas e sua relação histórico-cultural com o se - movimentar humano. Estas práticas são aqui utilizadas e interpretadas para demarcar o universo de estudo do movimento humano. Mais especificamente, quando este movimentar-se passa a ter métodos para o seu desenvolvimento. Quando o corpo e o movimento são qualificados não mais como algo natural, mas sim, como algo que pode ser melhorado, cuidado, desenvolvido e adquirido intencionalmente.

Os Parâmetros Curriculares Nacionais do Brasil - PCN (BRASIL, 1997) abordam que o trabalho nesta área tem seus fundamentos nestas concepções de corpo e movimento, ou seja, na compreensão desses dois conceitos. O corpo que se relaciona dentro de um contexto sociocultural e o movimento como produto dessa interação.

Ao que se refere em discutir o corpo, o compreende-se como construção cultural e sede de signos sociais, posto que "cada sociedade se expressa diferentemente por meio de corpos diferentes" (DAOLIO, 1995, p. 36). Desse modo, relaciona-se

\footnotetext{
${ }^{3}$ Adotando a ideia de Betti (1998), faz-se pertinente primeiramente estabelecer o cenário, para depois conseguir falar sobre ele.

${ }^{4}$ Uma teoria da prática pedagógica denominada Educação Física vai, necessariamente, ocupar-se da tensão entre o que vem sendo e o que deveria ser essa EF (COLETIVO DE AUTORES, op.cit.). Não é o grande objetivo desse texto fazer essa discussão sobre o que era e o que deve ser a EF, todavia deixo
} a sugestão para um possivel estudo. 
os saberes oriundos da EF à função ou ao "papel social a ela atribuído e que define em largos traços, o tipo de conhecimento buscado para sua fundamentação" (BRACHT, 2007, p. 43).

Desta forma, a EF vem se caracterizando como um espaço social de conflitos sobre as formas autorizadas de pensar e orientar modos de educação no, pelo, para, através e com o corpo. Conforme GONÇALVES (1994), o trabalho da EF precisa centrar-se nos sujeitos como um todo, buscando compreender suas expressões e sentimentos, sua complexidade e ação do corpo e do movimento.

Um corpo que sente, expressa, comunica, cria e significa. 0 que a difere de outras áreas do conhecimento, ou seja, sua especificidade está em conferir importância e legitimidade no cuidar o corpo, cientificamente e pedagogicamente (PAIVA, 2005). Ou seja, sobre os fazeres corporais legítimos, pedagógicos e pedagogizados produzidos na cultura.

ASSMANN (1994) inclui a corporeidade como categoria relevante para a relação pedagógica. Trazer a corporeidade para a práxis educativa, significa trazer a vida e as vivências para o processo educativo e convocar a pedagogia para pedagogizar a vida.

Sendo assim, a EF se configura como uma prática pedagógica que, no âmbito escolar, deve tematizar formas de atividades expressivas corporais (COLETIVO DE AUTORES, 1992), responsável pela constatação, demonstração, compreensão e explicitação de uma dimensão dessa realidade social, na qual, o aluno está inserido e que se denomina de cultura corporal (CASTELANI FILHO, 1998).

Pautados nessa reflexão, a Base Nacional Curricular Comum - BNCC (BRASIL, 2018), aborda a prática da EF,

"[...] como fenômeno cultural dinâmico, diversificado, pluridimensional, singular e contraditório. Desse modo, é possível assegurar aos alunos a (re)construção de um conjunto de conhecimentos que permitam ampliar sua consciência a respeito de seus movimentos e dos recursos para o cuidado de si e dos outros e desenvolver autonomia para apropriação e utilização da cultura corporal de movimento em diversas finalidades humanas, favorecendo sua participação de forma confiante e autoral na sociedade" (p.213).

Deste modo, a EF carece compreender os sujeitos em sua complexidade caracterizada no e pelo corpo. O conhecimento e as experiências corporais vivenciadas na sala de aula devem alcançar o cotidiano dos alunos, da escola e das famílias. A construção de um diálogo sobre a questão do corpo de forma interdisciplinar, que permita entender o corpo em toda a sua complexidade enquanto construção de um ser que é ao mesmo tempo biológico e subjetivo. Desenvolvendo o processo de ensino e aprendizagem sustentados no movimento, com contributos para acionar a curiosidade, o pensamento, os sentimentos e a ação prospectiva (AHLERT, 2010; PERES, 2009).

Nesse sentido, a EF não seria somente esporte, nem tampouco somente movimento, atividade física ou jogo. Ela passa a ser o conjunto desses e de outros elementos que, nesse universo do corpo/movimento, se denomina cultura corporal de movimento $(\mathrm{CCM})^{5}$. Na consequência disto, a EF não atingiria o status de uma ciência, mas sim marcá-la-ia como uma área de conhecimentos relativos à CCM (BETTI, 1998) e que, portanto, carregaria as virtudes e fragilidades de uma área ancorada nas práticas sociais.

${ }_{5}^{5}$ Para uma análise mais aprofundada do termo ver Bracht (2005)
Bracht (2007), destaca que a necessidade e a reivindicação de fundamentar "cientificamente" a EF, conduziu a incorporação das práticas científicas ao campo acadêmico, o que não significa que a área passou a ser uma ciência com estatuto epistemológico próprio. Diante disso, compreende-se ainda a EF escolar como um espaço pedagógico que deve se apropriar de um saber específico, numa tarefa pedagógica específica, possibilitando o aluno vivenciar diversas práticas corporais.

A $\mathrm{CCM}^{6}$ é hoje o fenômeno de estudo do qual trata a $\mathrm{EF}$, com maior consenso dentro da área (PICH, 2005). Este consenso se estabelece, inicialmente, por ela constituir uma parte da totalidade da cultura humana que necessita ser tematizada no contexto escolar. Ela é um dos maiores patrimônios da sociedade contemporânea.

$\mathrm{Na} E \mathrm{~F}$, o conjunto de manifestações culturais, provindas destas práticas sociais, enquanto construções históricas, produzidas e ressignificadas, são os objetos de estudo a serem desenvolvidos e tematizados nesta área de conhecimento.

Aceitando e incorporando a CCM como o universo de estudo da EF (BETTI; 1998; COLETIVO DE AUTORES, 1992; SOARES, 1996; PCN, 1997; entre outros), dois pontos merecem aqui serem destacados: o primeiro deles, de certa forma, caracteriza abertamente, a ruptura de uma EF reacionária, instrumental, utilitarista, alienante e ideologista (influenciadas pelas teorias tradicionais, positivistas e ideologistas) para uma EF crítica, revolucionária, progressista e emancipatória (teorias críticas da educação). Já o segundo ponto que se destaca, centra-se na tentativa da

[...] área ultrapassar a ideia única de estar voltada apenas para o ensino do gesto motor correto. Muito mais que isso, cabe ao professor de Educação Física problematizar, interpretar, relacionar, compreender com seus alunos as amplas manifestações da cultural corporal, de tal forma que os alunos compreendam os sentidos e significados impregnados nas práticas corporais (DARIDO, 2001, p. 20).

Ao estipular a CCM como objeto da EF no contexto escolar, tem-se por finalidade o avanço do fazer corporal (saber fazer) para um saber sobre o se - movimentar humano (BETTI, 2005). Referenciando a EF na CCM sobre este se - movimentar humano é que, em linhas gerais, possibilitou grandes avanços na área. Principalmente no sentido de superar a perspectiva reducionista de concepção de movimento e de ser humano (PICH, 2005).

Todavia, ao superar esta perspectiva fisiológica-biológica de encarar o movimento, o ser humano e sinalizar a CCM, o universo de estudo da EF, se possibilita justificar e, por conseguinte, alcançar a legitimidade da sua presença como componente curricular na escola?7 O que poderia contribuir para a sua legitimação? Buscando mais elementos para responder a este questionamento e posicionando-se para o universo de análise e estudo da EF como sendo a CCM, a intenção agora passa por tentar argumentar a tematização deste conjunto de saberes no âmbito escolar.

${ }^{6}$ Nas delimitações desse texto, entende-se CCM como sendo o "acervo das formas de representação do mundo que o homem vem produzindo no transcurso da história, exteriorizadas pela expressão micas e outros, danças, lutas, exercicios ginásticos, esportes, malabarismos, contorcionismos, mvividas pelo homem, historicamente criadas e culturalmente desenvolvidas" (COLETIVO DE AUTORES, 1992, p. 38)

${ }^{7} \mathrm{Em}$ uma concepção mais ampliada, não pretendemos absolutizar a ideia de que tendo um universo de estudo, a legitimidade "entraria no pacote". Porém, também não podemos negar que, ter esse universo de estudo delimitado, contribuiria significativamente para a sua legitimação. Por outro lado, pouco sacralizá-lo, mas sim, fazer com que assuma a sua responsabilidade perante isso. 


\section{Por que ensinar EF na escola? Por que ela faz parte do currículo escolar?}

"[...] a presença da EF na escola como uma matéria de ensino, traz uma adorável, uma benéfica e restauradora desordem naquela instituição" (SOARES, 1996, p. 7).

De acordo com Bracht (2003), a EF deve ser entendida como prática pedagógica de intervenção direta na sociedade ${ }^{8}$ e que, portanto, deve assumir a responsabilidade do ensino dessas práticas sociais. Na escola, a EF deve integrar um contexto amplo, algo que vai além da sua própria disciplina. Tem por finalidade propiciar os alunos a apropriação crítica da CCM, visando formar o cidadão que possa usufruir, compartilhar, produzir, reproduzir e transformar as diversas formas culturais manifestadas pela motricidade humana (BETTI, 2005)

A razão de sua presença como componente curricular deve estar articulada aos objetivos da escola, visto que ela se insere em uma estrutura (social, econômica, religiosa, cultural, escolar etc.), que condiciona o processo de certas demandas, as quais o ambiente escolar necessita dar conta. Não na relação da escola estar subordinada a essas demandas da sociedade, mas sim, na forma de pensá-las e tematizá-las articuladamente.

Nesta forma de ressignificá-las é que Habermas (1989 apud FENSTERSEIFER, 2001), apresenta três grandes estruturas simbólicas do mundo da vida, que estão presentes nesse processo de tematização, que devem ser desenvolvidos na escola. Essas estruturas são: a cultura, a sociedade e a personalidade ${ }^{9}$. Para esse autor, tais estruturas "reproduzem-se por meio do prosseguimento de saber válido, da estabilização de solidariedades grupais e da formação de atores capazes de responder por seus atos" (p. 240). O desenvolvimento dessas estruturas são aspectos universais e possibilitam a constituição do ser humano.

O grande desafio da escola (ou um dos) é integrar, na sua composição curricular, unidades curriculares que permitam garantir melhores entendimentos sobre essas estruturas;

[...] a escola, segundo Boufleur, constitui-se em espaço de interação, onde, "de forma intencional e planejada, as novas gerações recebem o aprendizado relativo à tradição cultural, à inserção na sociedade e à formação da personalidade"; dimensões denominadas por Habermas de "estruturas simbólicas do mundo da vida" as quais deveriam balizar nossas intervenções pedagógicas, seja na escolha dos conteúdos, seja no trato metodológico, constituindo-se também num referencial apropriado para pensarmos o que tem sido a prática pedagógica na educação física, ou seja: estamos propiciando ao nosso aluno apropriar-se da tradição cultural, ou estamos limitando nossos conteúdos a modismos ditados pela mídia e, ainda pior, de forma acrítica? De que forma preconizamos a inserção de nossos alunos na sociedade? Que concepções de cidadania orientam nosso trabalho? E ainda, as metodologias que utilizamos têm em vista a capacidade de reprodução de conteúdos tidos como acabados, ou privilegiamos a autoformação? (FENSTERSEIFER, 2001, p. 241).

Se a cultura é "uma teia de significados na qual nós nos in serimos tecendo-a" (GEERTZ apud FENSTERSEIFER, 2005, p.2) e, sabendo que currículo, além de ser um curso a ser seguido, é num sentido geral e abstrato, a dimensão cognitiva e cultu-

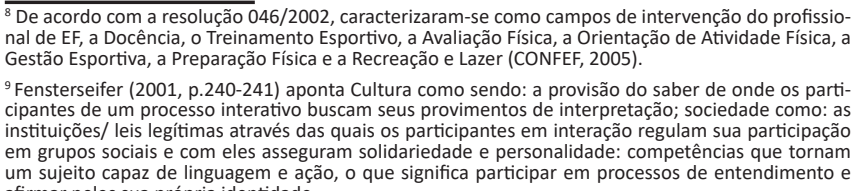
De acordo com a resolução 046/2002, caracterizaram-se como campos de intervenção do profissioGestão Esportiva a Preparação Física e a Recreação e Lazer (CONFEF, 2005).

${ }^{9}$ Fensterseifer (2001, p.240-241) aponta Cultura como sendo: a provisão do saber de onde os participantes de um processo interativo buscam seus provimentos de interpretação; sociedade como: as em grupos sociais e com eles asseguram solidariedade e personalidade: competências que tornam um sujeito capaz de linguagem e aça
afirmar neles sua própria identidade. ral do ensino, ou seja, seus conteúdos, saberes, competências, símbolos e valores (SOUZA JUNIOR, 2001), a escola (mais especificamente a EF - objeto de reflexão deste texto) se torna uma das ferramentas que possibilitam um 'abrir os olhos' sobre essas diversas manifestações culturais e universais presentes na sociedade.

Tendo ciência de que "o ser humano, como sujeito do conhecimento, não tem acesso direto à uma compreensão de mundo" (SILVA, 1995, p. 90), a EF, nesse sentido, assume a responsabilidade por dar conta de uma fatia de entendimento da sociedade, de mundo, ou seja, de análise disso. Em outras palavras, produzir esclarecimentos sobre a CCM.

Sabendo que o currículo é fruto de uma seleção da própria cultura, destinada a ser transmitida às novas gerações (FORQUIN apud SOUZA JÚNIOR, 2001), compete a EF tematizar os saberes acerca da sua parcela da cultura humana. Como,

[...] todo e qualquer indivíduo nasce no contexto de uma cultura, não existe homem sem cultura, mesmo que não saiba ler, escrever e fazer contas. É como se se pudesse dizer que o homem é biologicamente incompleto: não sobreviveria sozinho sem a participação das pessoas e do grupo que o gerou (PCN, 1997, p. 26).

$\mathrm{Na}$ atualidade, não se concebe se não essa ser a razão da EF estar na escola e ser um componente curricular, o que acaba por justificar sua presença no projeto político pedagógico. A EF assume a responsabilidade de formar o cidadão capaz de posicionar-se criticamente sobre a CCM. Essa condição é maior do que tentar alcançar sua justificativa e legitimidade por meio do esporte (de rendimento na maioria das vezes) ou da aptidão física, ou da atividade física (promoção da saúde), ou do desenvolvimento motor (BETTI, 1998). Desse modo, a EF desenvolvendo o entendimento de CCM na sociedade, assumindo sua parte de esclarecimento sobre o mundo, contribuirá significativamente com a formação humana integral desses alunos.

\section{Quais são as possibilidades de conhecimento em Educação Física: o dilema entre o saber científico e o saber do senso comum}

O fato de qualquer um ser capaz de ensinar alguma coisa (inclusive de inevitavelmente ensinar algo a alguém em sua vida) não quer dizer que qualquer um seja capaz de ensinar qualquer coisa. A instituição educacional aparece quando o que é preciso ensinar é um saber científico, não meramente empírico e tradicional (SAVATER, 1998, p. 54).

Se, na primeira parte deste texto discutiu-se sobre o objeto de estudo da EF, na segunda parte, sobre a sua importância (lugar de pertencimento) no sistema de ensino, como componente curricular, nessa terceira parte, faz-se importante discutir as suas condições de possibilidade de conhecimento para superar o dilema entre o saber científico e o saber do senso comum.

A primeira perspectiva é, portanto, reconhecer que o aluno na escola aprende conteúdos que não aprende brincando com os amigos, ou por meio das plataformas digitais e redes sociais (VARGAS LLOSA, 2012; MARTINY; SAWITZKY; GASPAR, 2020). Para tal, um primeiro princípio norteador é de que as aulas devem contemplar, sistematicamente, conteúdos que conduzam o aluno a agir de forma crítica e reflexiva ${ }^{10}$.

O aluno enquanto sujeito do processo de ensino deve ser capacitado para sua participação na funciona vida, através de uma reflexão crítica (KUNZ, 1994, p. 30). 
É nesse sentido que a $E F$, vai se encontrar dentro de um "campo de tensão" (vulnerável para alguns e não reconhecido por outros) de ter que confrontar o seu universo de estudo com um conhecimento que (supostamente) pode ser aprendido fora da escola. Isto visto que, o seu objeto de estudo provém desses ambientes sociais e, na maioria das vezes, se confunde com eles. Na lógica contrária a crítica positivista (Popper, 1999) seria, portanto, uma realidade com sujeito e objeto conhecido.

Martiny, Sampaio e Sawitzky (2019), reconhecem esse conflito sobre o saber a ser ensinado nas aulas em virtude das crenças que os alunos trazem sobre a área e como consequência disto, sobre os seus conteúdos.

Por considerarem os saberes ensinados em educação física muito aproximativos à realidade ao qual vivenciam e dominam, não só não reconhecem o valor real do que aprendem como também determina a) o reconhecimento acerca do nível de complexidade do componente (tendem a achar fácil), b) o nível de envolvimento desprendido (tendem a fazerem um envolvimento superficial, quando comparados, por exemplo, as disciplinas consideradas mais "difíceis" dentro do sistema de ensino) e, por fim, c) sobre o nível de estudo destinado (quando pensamos nas horas que passam/passariam estudando para cumprir as exigências do componente curricular (MARTINY et al., 2019, p. 152).

Dois pontos importantes surgem neste momento: o primeiro deles é a necessária confrontação do saber proveniente do senso comum (saber popular) com o conhecimento científico (saber sábio). SANTOS (2003; 2006), considera esse confronto através do diálogo, reencontro entre estas duas culturas de conhecimento (senso comum e senso científico), para assim constituir um novo formato do saber, na qual, o senso comum ignorante ou ingênuo, sede lugar a um senso comum esclarecido e a ciência dogmática, superior, elitista, a uma ciência mais prudente e democrática, desse modo sem hierarquizar estes saberes.

Para o Coletivo de Autores (1992), essa tensão entre as duas diferentes matrizes sociais do saber (popular e acadêmico) é do ponto de vista educacional-metodológico, fundamental para a reflexão pedagógica, visto que, instigaria o aluno, ao longo de seu processo de escolarização, e construir formas mais elaboradas de pensamento. A escola seria, portanto, o agente de tensionamento (o elo) entre o saber científico e o saber do senso comum (Figura 1).

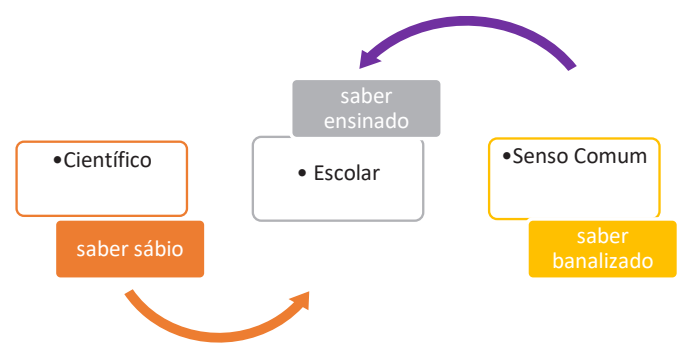

Figura 1. A relação do saber ensinado, saber sábio e saber banalizado (Aadaptado de Martiny, 2012).

O segundo ponto que decorre como consequência deste primeiro é a necessária transposição didática dos saberes científicos para se tornarem saberes escolarizáveis ${ }^{11}$. Um processo que para as áreas ditas humanas/sociais não é tão claro e fácil. Assim como aponta Perrenoud (2002),

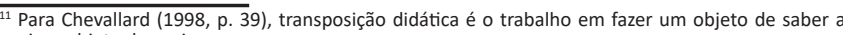
ensinar objeto de ensino.
[...] a transposição dos saberes acadêmicos tenta permanecer o mais próximo possível do estado da pesquisa, tal como isso é definido pelas instituições científicas mais legítimas. A referência é clara, porque, em nossa sociedade, a ciência está organizada. Há instituições e mídias autorizadas a serem suas porta-vozes: as universidades, os centros de pesquisa, as sociedades acadêmicas, as revistas e os acervos científicos reconhecidos [...]. [Porém], a acepção corrente da noção de transposição na didática das matemáticas, por exemplo, refere-se à escolarização de saberes acadêmicos. Pode-se utilizar o mesmo raciocínio em disciplinas como história, geografia, biologia, física, química ou economia: é preciso extrair programas adaptados a uma determinada faixa etária e a um determinado curso de um corpo identificado de saberes teóricos. O problema se complica no caso das línguas. Todos sabem que a linguística rege apenas uma parcela limitada dos conteúdos [...]. Em essência eles não são a transposição dos saberes acadêmicos, mas normas e práticas sociais da língua, materializadas, sobretudo, nos corpus dos escritos sociais e das práticas orais [corporais] (p. 75 grifo do autor)

Reconhece-se, portanto, o grau de dificuldade em configurar as práticas corporais como textos do saber (leitura e interpretação) acerca do corpo e do movimento humano como linguagem. A noção de linguagem aqui assume, portanto, a ideia de um sistema simbólico que nos permite explicar as experiências que o indivíduo tem, por meio do seu corpo em movimento na interação com o mundo (falando especificamente da EF)

O dilema entre o saber sábio e o saber do senso comum, seria, portanto, superado uma vez que a EF conseguisse explicar a experiencia corporal na confrontação entre objetividades cientificas (no aprofundamento da linguagem) e as percepções individuais (linguajar comum). Para Maturana (2002), o ato de explicar a experiencia - por meio da linguagem - é o primeiro passo para a elevação ao plano da consciência acerca do estado de conhecimento que é proveniente dela. Em outras palavras, caberia a escola em um sentido geral e nas aulas de EF, em um sentido restrito, colocar o aluno como um observador da sua própria experiência. Faria, portanto, com que o aluno, não somente refletisse sobre ela, mas que a reconhecesse com certo grau de interdependência e intersubjetividade. Com um olhar distante e ao mesmo tempo próximo, objetivo e ao mesmo tempo subjetivo ${ }^{12}$.

Essa condição evidenciaria, principalmente, segundo Martiny, Sawitzky e Gaspar (2020) que a educação física ensine, além de conjunto de saberes teóricos, um conjunto maior de saber sobre um saber corporal, que na sua maioria são acessados por meio da experiência prática direta, vivida e refletida. Um conjunto de saberes que só é e será relevado por meio dessa experiência corporal. Assim, empiricamente se materializando a necessidade de o corpo sentir (e refletir sobre esse sentir) para que uma experiência possa existir (BARROS FILHO; MEUCCl, 2014).

Não obstante e em caráter conclusivo-provisório, ter-se-ia aqui duas variáveis importantes. A diferenciação e a integração. Se, por um lado, marca-se a CCM como o objeto de estudo que diferencia a EF das outras áreas de conhecimento (pensando no currículo escolar) e que, assim sendo, Ihe atribuindo um núcleo identitário, uma especificidade, um campo de reflexão, pesqui-

12 Leite (2007) aponta, por exemplo, que a esfera da produção dos saberes move-se pela busca de resoluçâo de problemas colocados pela comunidade de pesquisadores, já a esfera do ensino não é impulsionada propriamente pela necessidade de solução de problemas, mas sim pela contradição antigo/novo. Essa contradição antigo/novo explica a necessidade de os objetos de ensino se remeterem àquilo que já é conhecido pelo aluno, ao mesmo tempo em que devem aparecer como novidade - afinal é o novo, é o não sabido que justifica a relação didática; porém, se o aluno não puder realizar algum tipo de reconhecimento ou identificação com os saberes que já domina, o estranhamento pode ocorrer em tais proporções que inviabilize o aprendizado. O objeto de ensino, então, tem o papel de objeto transicional entre passado e futuro. A superação desta contradição significa, portanto, saber que anteriormente se apresentava como novo. 
sa, problematização e saber, por outro lado, quando se busca na linguagem a explicação das experiências do corpo em movimento, é que ela vai se aproximar e se integrar a todas as outras áreas do saber.

A busca da linguagem para explicar as experiencias corporais geradas na CCM, tornam, ao nosso ver, a EF uma área do saber mais complexa. E não mais vulnerável ou confusa. Como consequência direta, ela caminharia, portanto, em um sentido contrário ao da atomização das disciplinas, da sua desintegração e mutilação, portanto, superando a sua patologia acerca do saber (SOBRAL, 1995).

O desdobramento da área, a sua evolução, a sua legitimidade, não viria pela busca exclusiva da sua diferenciação. As suas condições de possibilidade de conhecimento e por conseguinte, de legitimação, viriam pela sua articulação, pela sua crescente harmonização entre aquilo que a diferencia e aquilo que a integra, ou seja, o arranjo entre a cultura do movimentar-se do ser humano e a linguagem (enquanto experiência explicada).

A legitimação viria, portanto, pelo crescente ajustamento entre o vivido e o constructo psicossocial explicativo que o reifica (Figura 2). Estes constructos se explicariam pelo viés do conhecimento acerca do corpo humano, pela sistematização das práticas corporais presentes na sociedade e/ou pela representação social sobre a cultura do movimentar-se humano (GONZALEZ; FRAGA, 2012).

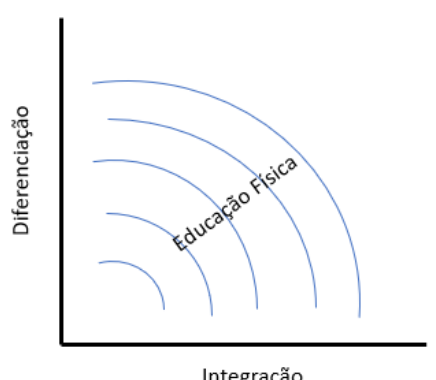

Figura 2. Complexidade da Educação Física (adaptado de CSIKSZENTMIHALYI, 1993).

Em um plano mais abrangente, a busca pela legitimação por meio da junção dessas duas variáveis transcenderia a própria área do saber e se alocaria dentro do sistema social. $\mathrm{Na}$ busca por um melhor convívio social. Que dialoga e reconheça tanto as singularidades individuais (e que vá para além delas) como as necessidades coletivas (CSIKSZENTMIHALYI, 1993).

\section{CONCLUSÃO}

Neste contexto, delimitamos esse texto na possibilidade da produção de argumentos que expliquem e exemplifiquem a legitimidade da EF na escola. Uma possibilidade de produzir convencimento por meio das contextualizações expostas aqui. As explicitações das ideias mencionadas não estão pautadas na intenção de esgotar os assuntos acerca da EF na escola.

Talvez, a apresentação dessas discussões tenha se estabelecido no campo do ideal. Todavia, ao apresentá-las relacionando-as à EF escolar, quiçá, podem-se sinalizar pequenas aproximações quanto à busca de sua legitimidade na escola.
Marcamos a busca da legitimação da Educação Escolar por meio da cultura corporal de movimento como linguagem por meio da sua condição de possiblidade de conhecimento. De leitura, reificação, interpretação e análise do mundo do movimento humano.

É importante destacar que essa é uma dentre tantas outras possibilidades. Entretanto, entendemos que a sua legitimação não viria pela busca hiper polarizada da sua individualização. Em outras palavras, ela não aconteceria pela atomização do seu saber a ser ensinado.

Ainda que preservando a sua singularidade, a legitimação da EF escolar viria pela superação das suas necessidades individuais. Desse modo, ela aconteceria pela sua relevância social e sua capacidade de integração a um projeto coletivo que priorize a construção de uma sociedade que reconheça a importância da formação de uma identidade coletiva.

O grande desafio que deixamos nesse trabalho é conseguir realizar investigações e intervenções pedagógicas que consigam dar conta de apresentar os conteúdos da CCM nas aulas de EF. Ao desenvolver ao menos uma grande parte deles nas aulas de EF, se possibilitará a inserção do aluno em uma parcela de entendimento de mundo, ou seja, de análise e compreensão deste.

\section{REFERÊNCIAS}

AHLERT, A. Corporeidade e educação: o corpo e os novos paradigmas da complexidade. Caderno de Educação Física, Marechal Cândido Rondon, v. 9, n. 17, p. 113-26, 2010.

ASSMANN, H. Paradigmas educacionais e corporeidade. 2. ed. Piracicaba: UNIMEP, 1994.

BARROS FILHO, C.; MEUCCI, A. A vida que vale a pena ser vivida. 11. ed. Petrópolis: Vozes, 2014

BETTI, M. A janela de vidro. Campinas: Papirus, 1998

BETTI, M. Educação física. In: GONZELEZ, F. J.; FENSTERSEIFER, P. E. Dicionários crítico de educação física. Ijuí: Unijuí, 2005. p. 144-50.

BRACHT, V. Cultura corporal, cultura de movimento ou cultura corporal de Movimento: In: SOUZA JÚNIOR, M. (Org.). Educação física escolar: teoria e política curricular, saberes escolares e proposta pedagógica. Recife: Edupe, 2005. p. 97-106.

BRACHT, V. Educação física \& ciência: cenas de um casamento (in) feliz. 2. ed. Ijuí: Unijuí, 2003.

BRACHT, V. Educação física escolar: saber e legitimidade: In: BRACHT, V. (Org.). Pesquisa em ação: educação física na escola. Ijuí: Unijuí, 2003. p. 51-59.

BRASIL. Ministério da Educação. Base Nacional Comum Curricular. Brasília, 2018. Disponível em: <http://basenacionalcomum.mec.gov.br/>. Acessado em: 22 de julho de 2021.

BRASIL. Secretaria de Educação Fundamental. Parâmetros Curriculares Nacionais: Educação Física. Brasília. MEC, 1997. Disponível em: <http:// portal.mec.gov.br/seb/arquivos/pdf/livro01.pdf>. Acessado em: 22 de julho de 2021.

CASTELLANI FILHO, L. Política educacional e educação física. Campinas: Autores Associados, 1998.

CHEVALLARD, Y. La transposición didáctica: del saber sabio al saber enseñado. 3. ed. Buenos Aires: AIQUE, 1998.

COLETIVO DE AUTORES. Metodologia do ensino de educação física. São Paulo: Cortez, 1992.

CONFEF. Conselho Federal de Educação Física. Personal training: respeito às individualidades e limitações. Revista E. F., Rio de Janeiro, v. 5, n. 15, p. 1-10, 2005

CSIKSZENTMIHALYI, M. The evolving self: a psychology for the third milenium. New York: Harp and Colins, 1993 
DAOLIO, J. Da cultura do corpo. Campinas: Papirus,1995.

DARIDO, S.C. Os conteúdos da educação física escolar: Influências, dificuldades e possibilidades. Perspectivas em Educação Fiísica Escolar, Niterói, v. 2, n. 1 (Suplemento), p. 5-21, 2001

FENSTERSEIFER, P. E. A tarefa educacional na especificidade da escola. ljuí: Unijuí, 2005.

FENSTERSEIFER, P. E. A educação física na crise da modernidade. ljuí: Unijuí, 2001.

GALLARDO, J. S. P. Educação física escolar: do berçário ao ensino médio. 2. ed. Rio de Janeiro: Lucerna, 2005.

GONÇALVES, M. A. S. Sentir, pensar, agir: corporeidade e educação. Campinas: Papirus, 1994

GONZALEZ, F. J.; FENSTERSEIFER, P. E. Dicionário crítico da educação física. ljuí: Unijuí. 2005.

GONZALEZ, F. J.; FRAGA, A. Afazeres da educação física na escola: planejar, ensinar, partilhar. Porto Alegre: Edelbra, 2012

GRESPAN, M. R. Educação Física no ensino fundamental: primeiro ciclo. Campinas: Papirus, 2002

GUIRALDELLI JÚNIOR, P. Educação física progressista: a pedagogia críticosocial dos conteúdos e a educação física brasileira. 2. ed. São Paulo: Loyola, 1989.

KUNZ, E. Transformação Didático-pedagógica do esporte. ljuí: Unijuí, 1994.

LEITE, M. S. Recontextualização e transposição didática: introdução à leitura de Basil Bernstein e Yves Chevallard. Araraquara: Junqueira \& Marin, 2007.

MARTINY L. E A transposição didática na educação física escolar: a prática pedagógica dos professores em formação inicial e a relação com seus saberes docentes. 2012. 173f. Dissertação (Mestrado em Educação Física) - Universidade Estadual de Pernambuco/Universidade Federal da Paraíba, Recife/João Pessoa, 2012

MARTINY, L.; SAMPAIO, A. K. SAWITZKI, R. A transposição didática na educação física escolar: In: SAWITZKI, R.; MARTINY, L.; JAEGER, A. (Org.). Vida, vivência e experiencia de professores de educação física. Coleção educação física escolar. Curitiba: CRV, 2019. p. 125-42.
MARTINY L · SAWITZKI, R · GASPAR, P As práticas inovadoras na educação física como condições de possibilidades para um estado de gratificação na docência: In: SAWITZKI, R.; BORGES, R.; MARTINY, L. (Org.). Vida, vivência e experiencia de professores de educação física. Coleção educação física escolar. Curitiba: CRV, 2020. p. 21-42.

MATURANA, H. Emoções e linguagem na educação e na política. Belo Horizonte: UFMG, 2002

PAIVA, F. S. L. Campo da Educação Física. In: GONZÁLEZ, F. J.; FENSTERSEIFER, P. E. Dicionários crítico de educação física. ljuí: Unijuí, 2005. p. 54-56.

PERES, L. S. Corporeidade e sua relação com a educação física: um breve resgate histórico para entendimento. Caderno de Educação Física, Marechal Cândido Rondon, v. 8, n. 15, p. 53-61, 2009.

PERRENOUD, P. A prática reflexiva no ofício de professor: profissionalização e razão pedagógica. Porto Alegre: Artmed, 2002.

PICH, S. Cultura corporal de movimento. In: GONZÁLEZ, F. J.; FENSTERSEIFER, P. E. Dicionário crítico de educação física. Ijuí: Unijuí, 2005. p. 108-111.

POPPER, K. Conhecimento objetivo: uma abordagem evolucionária. Belo Horizonte: Itatiaia, 1999.

SANTOS, B. S. Conhecimento prudente para uma vida decente: um discurso sobre a ciências revisitado. São Paulo: Cortez, 2006.

SANTOS, B. S. Um discurso sobre as ciências. São Paulo: Cortez, 2003.

SAVATER, F. O valor de educar. São Paulo: Martins Fontes, 1998.

SOARES, C. L. Educação física escolar: conhecimento e especificidade. Revista Paulista de Educação Física, São Paulo, Suplemento 2, p. 6-12, 1996.

SOBRAL, F. Cientismo e credulidade ou a patologia do saber em ciências do desporto. Movimento, Porto Alegre, v. 2, n. 3, p. 7-16, 1995.

SOUZA JÚNIOR, M. (Org.). Educação física escolar: teoria e política curricular, saberes escolares e proposta pedagógica. Recife: Edupe, 2005.

SOUZA JÚNIOR, M. O saber e o fazer pedagógico da educação física na cultura escolar: o que é um componente curricular? In: CAPARRÓz, F. E. (Org.). Educação Física Escolar: política, investigação e intervenção. Vitória: Proteoria, 2001. p. 81-91.

VARGAS-LLOSA, M. A civilização do espetáculo: uma radiografia do nosso tempo e da nossa cultura. Rio de Janeiro: Objetiva, 2013.

\section{CONFLITO DE INTERESSE}

Os autores do estudo declaram não haver conflito de interesses.

\section{FINANCIAMENTO}

Este estudo não recebeu apoio financeiro.

\section{ORCID E E-MAIL DOS AUTORES}

Luis Eugênio Martiny

ORCID: 0000-0002-0644-1726.

E-mail: luis_martiny@hotmail.com

Larissa Zanetti Theil (Autor Correspondente)

ORCID: 0000-0002-7616-4082.

E-mail: larissa.theil@iffarroupilha.edu.br

Eloy Maciel Neto

ORCID: 0000-0002-3784-1677.

E-mail: eloymacielneto@gmail.com 